\title{
Processes and integration in the interaction of purchasing and marketing: Considering synergy and symbiosis
}

\author{
Mark A. Toon ${ }^{\mathrm{a}, *, 1}$, Robert E. Morgan ${ }^{\mathrm{a}, 1}$, Adam Lindgreen ${ }^{\mathrm{a}, 1}$, Joëlle Vanhamme ${ }^{\mathrm{b}, 1}$, Martin K. Hingley ${ }^{\mathrm{c}, 1}$ \\ a Cardiff Business School, Cardiff University, Colum Drive, Cardiff CF10 3EU, United Kingdom \\ b EDHEC Business School, 24 Avenue Gustave Delory, CS 50411, 59057 Roubaix Cedex 1, France \\ c Lincoln Business School, University of Lincoln, Brayford Pool, Lincoln LN6 7TS, United Kingdom
}

\section{A R T I C L E I N F O}

\section{Article history:}

Accepted 5 May 2015

Available online $\mathrm{xxxx}$

\section{Keywords:}

Functional integration

Interface

Internal integration

Purchasing

Relational

Transactional

\begin{abstract}
A B S T R A C T
Effective integration of both purchasing and marketing functions is central to effective value creation and alignment of an organization with its business environment. Rapidly changing environments create gaps in the value creation process that compromises the delivery of value to the customer and risk misalignment of value propositions to their needs. Despite the clear imperative for research in this area, the extant literature is partial and delivers limited coherence. Ours is a theoretical article that-in drawing on previous literature-introduces the new work collected in this special issue and considers this against our own empirical evidence. We present a framework that maps out the landscape of internal organizational integration with a particular emphasis on purchasing and marketing integration. Implications for theory and managers are explored.
\end{abstract}

(c) 2015 Published by Elsevier Inc.

\section{Introduction \& background}

In terms of the study's background, marketing and purchasing theory has emerged in recent decades providing both additional insight and alternative perspectives to traditional economic explanations of organization performance (Bocconcelli \& Tunisini, 2012; Bregman, 1995; Coviello, Brodie, Danaher, \& Johnston, 2002; Kotler \& Levy, 1973; Lindgreen, Vanhamme, van Raaij, \& Johnston, 2013). While this insight and these perspectives originate from different standpoints, commonality exists in efforts to remove boundaries between the organization and its external constituencies and, importantly, within the organization (Dess, Rasheed, McLaughlin, \& Priem, 1995). These so-called boundary-less conditions are held to facilitate better co-operation, superior products and services, and increasingly, more effective cocreation of value (Bregman, 1995; Gummesson \& Polese, 2009; Kotler \& Levy, 1973).

The interface between the organization and the customer on the one hand and between the organization and the supplier on the other has received extensive attention in literature, as organizations have moved to outsource non-core activities (Sheth, Sharma, \& Gopalkrishnan, 2009).

\footnotetext{
* Corresponding author.

E-mail addresses: toonm@cardiff.ac.uk (M.A. Toon), morganre@cardiff.ac.uk (R.E. Morgan), lindgreena@cardiff.ac.uk (A. Lindgreen), joelle.vanhamme@edhec.edu (J. Vanhamme), mhingley@lincoln.ac.uk (M.K. Hingley).

${ }^{1}$ All authors contributed equally.
}

Such strategic external relationships should, it is argued, be reflected by similar strategic internal relationships between the primary functions of purchasing and marketing (Piercy, 2009).

The integration of primary functions within the organization is an important, but under-researched area (Bocconcelli \& Tunisini, 2012) despite obvious benefits for practitioners such as improved organizational performance through cost efficiencies and better alignment with the market (Bregman, 1995; Sharma \& LaPlaca, 2005), improved product development (Khan \& Mentzer, 1998), and greater organizational agility in competitive business environments (Piercy, 2009). The marketing and purchasing functions in particular represent the conduits between an organization and its external constituencies, and integration of these primary functions offers particular benefits to the organization as a result.

In considering the aforementioned issues, we draw on the range of extant work paying particular attention to the classification of purchasing practices (Lindgreen et al., 2013) and the parallel outline of marketing practices (Coviello, Brodie, Danaher, \& Johnston, 2002). We further draw on the latest work presented in Industrial Marketing Management's special issue on co-management of purchasing and marketing; and we augment this with our own case evidence derived from a UK-based electrical appliances manufacturer. Specifically, our article contributes to current literature by formulating a hybrid classification of purchasing and marketing practices. A typology of integration approaches further augments this contribution. The implications for theoretical development of the important area of co-management of purchasing and 
marketing are explored through our hybrid classification - integration approaches framework. Finally, our article contributes to current literature on a more practical level by addressing implications for practitioners.

\subsection{Rationale for the study}

Purchasing and marketing traditionally have operated as separate and distinct functions with discrete operational agendas within the same organization. This atomistic approach stems in part from a legacy of organizational activities based on exchange of goods in which purchasing focuses on upstream supply partners while marketing consider downstream attention and consider the customer (Sheth et al., 2009; Vargo \& Lusch, 2004). An increasingly dominant role of service in all activities combined with greater innovation in the business environment has brought about reduced cycle times and a change in the demands on the purchasing and marketing functions. These changes require agility and necessitate a more flexible organizational architecture including the softening of boundaries between functions internally, bringing purchasing and marketing activities closer together in order to deliver more value in less time (Gulati \& Oldroyd, 2005; Hingley, Lindgreen, \& Casswell, 2006; Srivastsava, Shervani, \& Fahey, 1999).

Much progress has been made in the effective integration of purchasing and marketing with their external constituents. Outsourcing of non-core activities in pursuit of agility is one driver of this and raises the strategic importance of the integration process. Mutual adaptation between the organization and external constituencies informs the value delivery process (Viio \& Grönroos, in press). As agility in external integration activities becomes the new norm, the advantage available through this route narrows for the individual organization. Internal integration brings the prospect of a new frontier in advantage and one that has the additional benefit of being under the complete jurisdiction of the manager. The slow adoption of internal integration, and between purchasing and marketing in particular, presents an opportunity for clear advantage for the organization that can exploit it.

Limits to agility for the organization include a lack of flexibility in internal relationships between functions. Successful work in closing the gap between the organization and its external constituents is not generally repeated internally by a closing of the gap between purchasing and marketing. This reduces effective organizational response to the changing business environment (Khan \& Mentzer, 1998; Wind, 2005), impairing resource mobilization along the value chain (Ellegaard \& Koch, 2012), and reducing delivery of customer value (Flynn, Huo, \& Zhao, 2010). Functional integration enhances the flow of resources and internal activities such as information, money, and decisions, with the derived benefit of it aiding responsiveness and reducing cycle times (Flynn et al., 2010). The dynamic capabilities required in the dual and symbiotic focus on suppliers and customers represent a strategic asset (Ziggers \& Henseler, in press). Advantage is enjoyed by organizations that can generate solutions jointly among internal functions and this works in complement to established external integration (Wagner \& Eggert, in press).

Some notable examples of functional alignment are not new and include specific management systems such as total quality management or other quality assurance systems in which stages of the value chain are treated as internal customer constituencies and dyadic exchange is manifest within the organization (Krohmer, Homburg, \& Workman, 2002). These are generic functional integration tools, however, and sit alongside a developed literature on marketing and sales integration (Homburg, Jensen, \& Krohmer, 2008) and marketing and new product development integration (Ernst, Hoyer, \& Rubsaamen, 2010), while purchasing and marketing integration has received little specific attention. The aforementioned special issue on co-management of purchasing and marketing addressed this with specific contributions on purchasing and marketing integration (Gonzales-Zapatero, in press;
Matthyssens, in press; Wagner \& Eggert, in press; Ziggers \& Henseler, in press).

Where they occur, responses to the environmental challenges differ between purchasing and marketing. Marketing is linked more directly to the 'coalface' of consumer-led changes in the environment; and this downstream engagement interface has proselytized (Coviello, Brodie, Danaher, \& Johnston, 2002; Moorman \& Rust, 1999). Business-to-customer architectures have been joined by customer-to-business, and more complex scenarios such as customer-to-customer-to-business (Gummesson \& Polese, 2009). Against this backdrop, marketing acts as a driver in internal integration efforts (Achrol \& Kotler, 1999). Similar, but slower, changes have occurred in the purchasing function and are characterized by a shift from exchange-of-goods transactions to more relational interactions (Blonska, Storey, Rozemeijer, Wetzels, \& Ruyter, 2013; Sheth et al., 2009). As a slower responder to these environmental challenges, supply relationships are increasingly drawing on established marketing theory (Ellram \& Carr, 1994).

While rates of change by functions may differ, commonality exists in the solution to understanding the integration process. Successful integration requires understanding of two key domains: contextual dynamics governing the integration process and managerial approaches to implementing internal integration. Contextual dynamics such as the structure of the linkages and nature of communication (Coviello, Brodie, Danaher, \& Johnston, 2002; Homburg, Jensen, \& Krohmer, 2008; Lindgreen et al., 2013) are examples of the mechanisms by which functional integration takes place. For instance, structural linkages will include joint planning episodes and team work that will form part of the management processes in the organization, while the nature of communication may be governed by cultural norms and so form elements of the contextual dynamic of the firm (Blois \& Ivens, 2006).

Managerial approaches are classified by the level of transactionalism or relationalism that is evident within the organization (Blonska et al., 2013; Maurer, Bartsch, \& Ebers, 2011; Sheth et al., 2009). Some managerial approaches are based on high interpersonal interaction, while others are transactional in nature with little interaction among counterparts. Managerial approaches are not degrees along a continuum, however, since each organization will have a particular type of management approach according to its industrial context and particular history (Lindgreen et al., 2013). Instead a typology of managerial approaches can be identified, with each one characterizing a particular style of exchange between the purchasing and marketing functions.

To address the integration of purchasing and marketing theory we seek to review extant literature and derive our own integration of hitherto disparate perspectives on integration approaches. We set out a framework to address this gap. We outline the constituencies of the purchasing and marketing functions, classify the nature of the integration between them and outline the interactive business processes. Finally, we suggest routes forward in achieving a synergistic and symbiotic internal strategy and outline the benefits of an integrated organizational model that brings more responsive solutions and lower cost structures.

In developing a framework that identifies the key overarching themes and classifications in the field, we identify key articles that present conceptual anchor points for the framework, and we illustrate this with findings from a single case study that we undertook. The case was selected from the manufacturing sector in the UK. We sought a medium-sized business because it represents a category of organizations with formalized functional divisions that have not progressed to multi-divisional forms or similar decentralized complex organizational structures. Consequently, medium sized businesses suit our focus, as they are most likely to have characteristics desirable for internal integration, namely close geographic proximity between functions, integrated management structure, and simple formalized internal architectures. The case selected is a manufacturer of small electrical appliances that sources process inputs and distributes finished products, globally. Specifically, interviews took 
place with the senior executive responsible for both procurement and marketing functions. We used semi-structured questions and a two-stage interview process. The first stage examined the structure and configuration of the organization. We focused on the internal configuration of functions and on the external linkages between the organization and its upstream and downstream value chain partners. Within this first stage we sought to identify the core activities of the organization and the location of value creation. The secondstage interview explored the nature of the linkages between internal functions generally and purchasing and marketing in particular. The semi-structured questions were augmented at times with open questions to elicit details and to allow the interviewee to present further information that was relevant to the internal integration and that we might not have included within our assumptions.

\section{The internal dynamics of the firm}

Internal dynamics are the contextual factors common within organizations that provide a platform for the processes that take place in the value chain (Bocconcelli \& Tunisini, 2012). Naturally, the range of contextual factors is wide. For example, Coviello et al. (2002) and Lindgreen et al. (2013) each identify nine such factors. Our aim within this article is to tighten existing classifications and provide a framework with universal application that articulates the landscape of this field thereby establishing a reference point for the study of internal integration. We narrow the classification of contextual factors, or internal dynamics, to three core areas-structural, human, and situational dynamics, and explore definitions and conceptual meaning in these areas. We draw on extant literature to support this conceptual development and also draw on insights gained from our case investigation.

\subsection{Structural dynamics}

The integration of purchasing and marketing is determined in part by the architecture of the internal processes of the firm. Examples of such processes include formalization, joint planning, and teamwork (Homburg, Jensen, \& Krohmer, 2008). The architecture represents these immediate processes for integration of functional activities, and is also evident at a macro level within the firm and is drawn from appropriate vision and objectives through which integration efforts can be supported (Wind, 2005). This makes the integration of functions a strategic consideration within the firm, complementing external integration efforts and facilitating the allocation of suitable resources and reducing barriers to integration by providing a clear motivation (Bals, Hartmann, \& Ritter, 2009; Wagner \& Eggert, in press). Thus, internal organizational architecture is an important dynamic from which functional integration can be derived.

Resource allocation may be viewed as a facilitator of the benefits of internal integration that, along with effective leadership of functional teams, will facilitate the attainment of team goals. When derived from the strategic objectives, team goals interpret the objectives and implement them as integration activities generating improved firm performance (Trent \& Monczka, 2003). While this presents a reassuringly good plan, there is complexity in the application that may limit effectiveness. Resources may not be allocated effectively or at a sufficient level to facilitate cross-functional teamwork. The propensity of crossfunctional team members to contribute to these strategic objectives may also be hindered by the legacy of "identity, beliefs, and social ties" that managers retain into the new roles (Houston et al., 2001). That such factors exist and reduce the effectiveness of functional integration agendas is not necessarily surprising. What may be less apparent is the propensity for these factors to confound one another. For instance, complexity within procurement and other functional processes is a barrier to integration (Bals et al., 2009) and is confounded by a shortage of time available to managers and employees to gain understanding of the work of other functions.
Resource constraints are common to all but a few organizations, and solutions to the difficulties outlined above may rest in innovative solutions to these problems. Existing functional silos may not need radical change, and integration agendas could be achieved with specific 'linking processes' in order to bridge the gaps between functions (Wind, 2005). Examples include total quality management techniques and similar process management tools (Krohmer et al., 2002). Such approaches not only overcome issues surrounding functional complexity and managerial motivation, but also present the opportunity for exchange (Bals et al., 2009). In our case study of a UK-based electrical appliances manufacturer we find evidence of this type of innovative design in the internal organizational architecture. The purchasing and marketing functions traditionally have been mediated by an outsourced distribution function, slowing communication and interrupting data flows on product performance. Distribution in this example was not just delivery of goods, but also an essential communication and brand management opportunity with customers across markets. The internal processes were changed to address this, and an integrated procurement and marketing process was designed to facilitate better feedback on product failure rates and improve customer service. The alignment of the value proposition between the organization and customers was improved and resulted in an associated improvement in firm performance.

Structural dynamics encompass the nature and type of exchange linkages giving insight into the mechanics governing the interaction of counterparts. We introduce this explanation of exchange linkages and present it in our framework (Fig. 1) as one of our three forms of dynamics.

\subsection{Human dynamics}

Effective functional integration builds on the processes described above, and also requires some volitional exchange among members from both purchasing and marketing. Free flowing exchange and goodwill are an indication of a successful exchange process between counterparts. The motivation for such exchange is not entirely benevolent, however, and is predicated on expectations of return (Blau, 1964). The knowledge exchanged in the inter-functional processes is given freely, but with an expectation of reciprocity at some future point in time. These periods of time may be short in the case of a team project where members contribute to a flow of ideas or more periodic where the linking process is addressing planning or strategic milestones. Time periods will be well understood among counterparts, and failure to reciprocate in a timely manor will bring distrust and present as a barrier to future exchange (Gulati, 1995). Similarly, the equivalence in value terms of the knowledge shared is important and together these factors form conditions of the exchange process (Blau, 1964).

Within functional integration, the exchange process is conducted in a group context, and the critical conditions of exchange, reciprocity and equivalence will be determined by the group. The group will govern "what the members [...] should do, ought to do and are expected to do" (Homans, 1950, p. 123) thereby establishing an acceptable range of behaviors. These expectations of behavior, or norms, are specific to the organizational context and are governed by a process of social sanction whereby those deviating from the acceptable range of behavior will find their standing and influence in the group reduced (Homans, 1950). The consequent cohesion of the inter-functional group facilitates consensus building and, as a result, group goals can be established (Thibaut \& Kelley, 1959). This consensus will be guided by an understanding of the organizational objectives and the strategic goals mentioned earlier that are both communicated and understood throughout the organization.

Knowledge exchange is the dominant form of exchange in the functional integration process and generates direct effects on organizational performance (Day, 1999; Homburg, Jensen, \& Krohmer, 2008). Knowledge exchange facilitates the attainment of joint goals and promotes creation and delivery of customer value (Flynn et al., 2010). Shared 
M.A. Toon et al. / Industrial Marketing Management $x x x$ (2015) $x x x-x x x$

\begin{tabular}{|c|c|c|c|c|}
\hline \multirow[t]{2}{*}{$\begin{array}{l}\text { Forms of } \\
\text { Dynamics }\end{array}$} & \multirow[t]{2}{*}{ Theoretical Manifestation } & \multicolumn{3}{|c|}{ Managerial Approach to Purchasing - Marketing Co-Ordination } \\
\hline & & Transactional & Integrative & Co-Management \\
\hline $\begin{array}{l}\text { Structural } \\
\text { Dynamics }\end{array}$ & $\begin{array}{l}\text { Exchange linkages including } \\
\text { "formalization, joint planning, } \\
\text { and team work" (Homburg et } \\
\text { al., 2008) }\end{array}$ & $\begin{array}{l}\text { Pre existing systems of work and market } \\
\text { focus including competition have a } \\
\text { positive affect on clusters within the value } \\
\text { chain and so have particular application to } \\
\text { integration that extends along the value } \\
\text { chain externally to the organization (Teller } \\
\text { et al., 2015) }\end{array}$ & $\begin{array}{l}\text { Our empirical study of an electrical } \\
\text { appliance manufacturer revealed co- } \\
\text { location of internal functions and an } \\
\text { interwoven set of exchange processes }\end{array}$ & $\begin{array}{l}\text { Co-management systems is achieved } \\
\text { through internal systems in which } \\
\text { organization-wide knowledge-sharing } \\
\text { architecture is developed. Such internal co- } \\
\text { management measures may be more } \\
\text { successful when extended to additional } \\
\text { upstream and downstream zones (Wagner \& } \\
\text { Eggert, 2015) }\end{array}$ \\
\hline $\begin{array}{l}\text { Human } \\
\text { Dynamics }\end{array}$ & $\begin{array}{l}\text { Trust in exchange including } \\
\text { "information sharing" and the } \\
\text { nature of communication } \\
\text { underpinning cultural norms } \\
\text { (Blois \& Ivens, 2006) }\end{array}$ & $\begin{array}{l}\text { Knowledge exchange in transactional } \\
\text { management approaches observes a reach } \\
\text { that is typically predetermined by contract. } \\
\text { Communication is less frequent than in } \\
\text { integration and co-management } \\
\text { approaches with a predominance of formal } \\
\text { communication. }\end{array}$ & $\begin{array}{l}\text { Information is shared in the electrical } \\
\text { appliance manufacturer in an ongoing } \\
\text { process with stages of procurement and } \\
\text { marketing feeding into one another. This } \\
\text { generates an iterative value creation } \\
\text { process formed by continued knowledge } \\
\text { exchange and adjustment (Toon } \text { et al., } \\
\text { 2012) }\end{array}$ & $\begin{array}{l}\text { Relationalism in co-management facilitates } \\
\text { the structured inclusion of upstream and } \\
\text { downstream external value chain agents in } \\
\text { bringing about exchange-based adaptation } \\
\text { in the process (Viio \& Grönroos, 2015) }\end{array}$ \\
\hline $\begin{array}{l}\text { Situational } \\
\text { Dynamics }\end{array}$ & $\begin{array}{l}\text { Goal orientation, physical } \\
\text { location, institutional power } \\
\text { arrangements and cross- } \\
\text { functional knowledge. (Flynn } \\
\text { et al., 2010; Griffin \& Hauser, } \\
\text { 1996; Wind, 2005) }\end{array}$ & $\begin{array}{l}\text { Shared goal orientation will assist in the } \\
\text { value delivery to the customers. For } \\
\text { example dual orientation on customer and } \\
\text { supply bases represent strategic assets } \\
\text { from which the organization might attain } \\
\text { advantage (Ziggers \& Henseler, 2015) }\end{array}$ & $\begin{array}{l}\text { The co-location of internal functions and } \\
\text { adoption of singular goals supports } \\
\text { organization-wide strategic goals in the } \\
\text { electrical appliance manufacturer. Power is } \\
\text { not exercised internally and cross- } \\
\text { functional knowledge developed through } \\
\text { this close interaction }\end{array}$ & $\begin{array}{l}\text { Physical proximity and integration } \\
\text { incentives may be used to facilitate co- } \\
\text { management leading to effective shared } \\
\text { information and aligned decisions } \\
\text { (Gonzales-Zapatero, 2015) }\end{array}$ \\
\hline
\end{tabular}

Fig. 1. The process-interface framework for marketing and purchasing integration.

ownership of value generation across functions is an antecedent to relationship quality (Ulaga \& Eggert, 2006), while exchange is shown to generate value in the process (Toon, Robson, \& Morgan, 2012). Our case study demonstrates effective cross-functional value creation. The integration of purchasing and marketing improves the response times in the event of product failure and allows rapid replacement, which is an important feature of performance in this industry. The exchange of knowledge between purchasing and marketing functions is central to this and, in the words of a director of the firm, "procurement is the most important thing to uphold brand reputation." Knowledge extends to aspects of every stage of the process and is important to the creation and delivery of value.

The norm-based behavior couched in an organization's strategic goals and the benefits of the exchange of knowledge generate cohesion and cultural identity, as well as organizational success. The familiarity that develops among the cross-functional team becomes characterized by trust as repeated trusting actions are experienced (Maurer et al., 2011). Firm performance is driven by social capital and the resulting collaborative behavior (Carmeli \& Schaubroeck, 2006), but mediated by knowledge exchange (Maurer et al., 2011) and members of the group become embedded in the established norms (Granovetter, 1985). This reinforces the inter-functional culture and addresses in part the problem of retained social ties to the former non-integrated internal organization (Houston et al., 2001). Embeddedness within a group or network can be a limit to innovation and agility and so to new ideas and other creative input (Noordhoff, Kyriakopoulos, Moorman, Pauwels, \& Dellaert, 2011), a problem that may persist in the functionally non-integrated firm where individual functions experience embeddedness. For the internally integrated organization, and where the social ties and identity is organizational-wide rather than function-narrow, this can bring the benefits of team cohesion without the disadvantages of silo building (Houston et al., 2001).

Support exists in the literature for the link between collaborative behaviors and organizational performance. For example, in a study of 109 business units in the tele-communications industry Lui, Gong, and Liu (2014) identified a link between organizational citizenship behavior at management level and organizational performance. Similarly, Carmeli and Schaubroeck (2006) studied 116 management teams in a multiindustry study and concluded that collaborative behavior in these teams also drives organizational performance. One interpretation of this is that strategic goals are communicated and shared across functions within the organization re-enforcing the process of joint problem solving and efficient allocation of resources.

Knowledge is a central resource and a driver of organizational performance where it is apportioned appropriately. For example, sales forecasts and new product development activities featuring crossfunctional creative input (Williams, Giunipero, \& Henthorne, 1994). Knowledge is shared, based on trust and collaboration, and resulting adaptations are made to improve the value creation process, for example by making timely adjustments to the sales process (Viio \& Grönroos, in press). An absence of inter-functional conflict promotes the exchange of resources, including knowledge (Ruekert \& Walker, 1987). It is the synergistic combination of resources that together with procedural fairness promotes greater innovative outcomes within the organization and more timely response to changes in customer demands (de Ruyter \& Wetzels, 2000). This addresses the organizational agility and value alignment agendas, outlined above and is instrumental in delivering superior organizational performance.

Human dynamics encapsulates the trust or norm-based behaviors that underpin the exchange process. This represents a spectrum from closely engaged collaborative arrangements based on high levels of affective trust through to a more calculative arms' length arrangement in which interaction is governed by norms as the rules of the game by which counterparts must play if the interaction is to have an opportunity for success. These human dynamics enlighten understanding of patterns of behavior in functional integration and we present this here as the second of our three forms of dynamics in our framework (Fig. 1).

\subsection{Situational dynamics}

The final internal dynamic of the organization is the configuration of internal factors that predetermine the functional integration process. Both the ability of the functions to integrate and the propensity for them to do so is context determined and we label this the situational dynamic of the organization. The situational dynamic is a melting pot of factors that characterize the institutional position of the organization, and which collectively act as barriers to internal integration. Three principal factors, or groups of factors, can be identified within this melting pot, physical location and goal orientation, institutional power arrangements, and cross-functional knowledge.

Physical location and goal orientation may differ from one function to another. For instance, marketing may favor quick response times, 
while purchasing may take a longer-term perspective with emphasis on consistency of supply and supply chain relationship building. Such differing agendas can contribute to silo mentalities and different thought worlds in which organizational goals are viewed through different lenses and interpreted differently (Griffin \& Hauser, 1996; Sheth et al., 2009). In conventional manufacturing settings the physical location of the purchasing and marketing functions may be separate, a legacy of the traditional goods-in, goods-out process architecture. Good performance of individual functions is not enough to contribute to strategic performance (Reck \& Long, 1988), and physical distance between functions frequently limits collaboration and associated strategic contribution. For example, such separation reduces serendipitous interaction such as exchanges of information between functions limiting mechanisms that drive an organization's performance (Flynn et al., 2010; Griffin \& Hauser, 1996; Piercy, 2009). These temporal and physical characteristics reduce both effective functional integration and the intensity of exchange (Bocconcelli \& Tunisini, 2012).

Second, institutional power arrangements across functions may present differences in the functional balance of power. Such power imbalances re-enforce hierarchical and silo-type mentalities creating virtual societies within functions that are culturally distinct from one another (Griffin \& Hauser, 1996; Houston et al., 2001; Sheth et al., 2009). Such power-based barriers to functional integration are addressed in two ways. Strategy implementation efforts can generate reorganization of the administrative framework, changing reporting, and accountability structures.

For example, within our case study, the electrical appliances manufacturer experienced power imbalances across the value chain with a more powerful purchasing function allocating resources to the sourcing of good quality components and close supplier relationships. This addresses the agenda for quality in the electrical goods, but overlooked the role of proxy indicators of quality used by customers such as speed of response in the event of product failure. Closer functional integration addressed this with an information management system that relied on both functions to gather and act upon quality indicators. In this respect, the information management system required functions to directly contribute to and share knowledge and the removal of knowledge ownership by any one function undermined power imbalances. Power imbalances may also be addressed through the establishment of consistent intraorganizational norms and restructuring of working practices in the appliance manufacturer created new working practices and expectations of behavior or norms. Procedural fairness promotes relationalism between functions facilitating integration (de Ruyter \& Wetzels, 2000), while group-based normative behavior constrains the use of power (Cook \& Emerson, 1978).

The third factor is the role of cross-functional knowledge. Knowledge of other functional areas is central to the collaborative creation of value (Homburg, Jensen, \& Krohmer, 2008). Such knowledge is mobilized through close integration of functions and contributes at multiple levels (Ellegaard \& Koch, 2012). Operationally, such knowledge is necessary to achieve effective value creation and the perspectives of contributors from outside a function brings new ideas and approaches generating outcomes that are based around solution building rather than operational efficiency (Wind, 2005). Synergistic collaboration occurs generating more effective innovation where multiple functions contribute and ensures maximal delivery of value to the customer (Ernst et al., 2010; Flynn et al., 2010). Central to this process is the ability through cross-functional knowledge of functions to understand and respond to the implications of innovations on other functions.

Situational dynamics is a series of factors (and we identify three) that exist within the architecture of the organization and determine the process of interaction between functions. Close, collaborative interaction can be seen to take place where goal orientation and physical location are similar among internal functions, where power imbalances are minimal, and where a good level of cross-functional knowledge exists. Distance between functions occurs where any of these factors exist at higher levels. Managers may facilitate closer integration, if this is their goal, by addressing these factors through redesign of working practices within the organization. For example, functions can be relocated or more closely linked through a redesign of daily communications making such channels easier and a feature of daily work practice. Similarly, strategic objectives can be reiterated and reinterpreted by functional teams through a series of training workshops that carry the agenda of building assimilation in goal orientation across functions.

\section{Managerial approaches to purchasing and marketing co- ordination}

The philosophical fault line between transactional and relational approaches to managerial co-ordination has a strong foundation in the marketing literature and is a distinction presented in the present field of internal integration (Coviello et al., 2002; Lindgreen et al., 2013). The relational element of this dichotomy is conceptually broad and lacks consistent representation in the literature, however. We seek to articulate distinct classifications of managerial approaches and we divide the relational element into two: integrative and co-management. Thus we capture the range of managerial approaches from transactional to fully integrated and do so through the three classifications of transactional, integrated, and co-management.

\subsection{Transactional}

Transaction approaches to exchange do not attempt to integrate with exchange partners and instead pursue a singular, self-interest agenda based on a cost saving logic (Sheth \& Parvatiyar, 1995). In the external environment this facilitates effective partner selection assisting in cost control. When applied to the internal environment of the firm, the approach is limited by the absence of an internal market and with only one option for an exchange partner selection is not an option. Instead, a transaction approach among functions within the firm may support quality management approaches where functions act as exchange partners and have specific requirements of their supplier counterparts. For example, the procurement function must deliver process inputs to the operations function that meet pre-established parameters. Where there are direct links between these functions a transactional approach may serve this process well. In the case of purchasing and marketing the direct links do not always exist and so the transactional approach is not suited to all business contexts.

Transactional approaches to exchange place importance on the details of the agreed exchange process. This has inherent advantages in respect of quality and cost control. Exchange partners will be fully aware of their obligations in terms of the parameters of the process inputs which may be measured using process key performance indicators such as Shewhart charts and automated process controls in the case of production line arrangements (Krohmer et al., 2002). This assists in processes with little or only preplanned variance in the production process. Variations will occur through a formal planning process characterized by formal communications and emphasis on operational parameters rather than strategic goals of the organization.

While barriers to complex knowledge exchange exist in transactional scenarios, because of limited collaboration across details that are not predetermined or set out in contractual terms, some industrial contexts benefit from the transaction approach. Cost and quality control may be facilitated in less complex settings where customer requirements are more stable. For example, in partially refined food products in business-to-business settings the customers are buying a process input for their own operations. Within the supplying organization a dual focus on supply bases and customers is achievable and can bring strategic advantage through better attention to the customers cost and quality agenda (Ziggers \& Henseler, in press). 
Transactional managerial approaches to purchasing and marketing co-ordination do not generally address aspects of interactions that facilitate co-ordination of complex or dynamic value creation. They have a specific role, however, in settings where complexity is low and emphasis is on a known set of quality and cost criteria and where lower levels of innovation are expected. We present the transactional approach to purchasing and marketing co-ordination as the first of three categories of managerial approaches to this co-ordination in our framework (Fig. 1).

\subsection{Integrative}

Integrative managerial approaches are opposite in nature to the transactional approach. Functions work together either through designated inter-functional teams or through close regular formal and informal communication (Wynstra, Weggeman, \& van Weele, 2003). Functional goals are aligned with strategic priorities of the organization and have an inter-functional orientation in which one function will accommodate some priorities of exchange partners.

Control of quality and costs is achieved through mutual dependence and relational capital in which high levels of trust exist and govern individual and group behavior. This is limited by variations in perceptions of trusting behavior that may be influenced by differing expectations, and by conclusions drawn from partial observations since monitoring does not form a part of the relational control process. Further variability is introduced by a lack of detail in early negotiations. A proportion of the specifications are established by allowing the counterpart to select appropriate parameters secure in the knowledge that relational capital will ensure counterparts act in the best interests of their exchange partner even when not obligated to do so (Luo, 2002). A benevolent approach may not be an effective substitute for informed decision making and consequently decisions made by the counterpart may be suboptimal even where made in good faith.

Our electrical appliance manufacturer case study revealed difficulties in the actions of the procurement function where informal arrangements were made under an umbrella of relational capital and in the absence of clearly specified process requirements. The implications of this are that good intent was a substitute for clear communication, cross-functional knowledge and alignment between the value proposition and the customer (Gonzales-Zapatero, in press; Homburg et al., 2008; Maurer et al., 2011). The process for gathering and responding to customer feedback on product specification, performance, and product failure was poorly designed with low importance assigned to the speed with which this knowledge was shared with the marketing function. This was not a deliberate attempt to frustrate the work of the marketing department through silo building (Houston et al., 2001), but was a decision-making process that lacked understanding of other functions' internal requirements leading to poor decisions on the feedbackgathering process. Resolution was achieved through the adoption of an integrative approach to purchasing and marketing co-ordination with primary aims of aligning functional goals and cross-functional knowledge in order that new practice could be established that allowed joint problem solving across functions. Operationally, the functional goals were information gathering from customers and faster response time and, strategically, they were the maintenance of brand reputation and customer retention.

This gives us an example of the difficulties that can be encountered where counterparts act in good faith, but with limited knowledge. Integrated approaches generally are characterized by closer working systems and full knowledge of counterpart requirements and where this is in place it might reasonably be expected that the problems outlined will not occur or will occur to a very limited extent. The risks of such outcomes are also lowered by close regular interaction in which problems will be identified and acted on early in the process. The changes made in the case of the electrical appliances manufacturer in respect of the feedback information problems were based around full integration of procurement and marketing. The relationship capital remained, but closer working systems enabled knowledge to be shared more effectively and joint systems were developed to ensure that customer feedback information was systematized and acted upon jointly.

Steady repetitive manufacturing environments are ill suited for the integrative managerial approach. Quality and associated cost controls are not tight and such manufacturing contexts frequently address volume, undifferentiated products where margins are tight, and cost control is central to competitive advantage (Krohmer et al., 2002). In other contexts where the products vary frequently and have a short cycle times, adaptability is an advantage. Preplanning of change is difficult under these circumstances and, in the absence of formally communicated specifications, reliance falls to informal communication and joint problem solving. Integrated functions address problems at the design stage rather than during implementation thereby saving time and improving cycle times. Integrative approaches to co-ordination of purchasing and marketing is the second of our three managerial approaches presented in our framework (Fig. 1).

\subsection{Co-management}

Co-management approaches to the co-ordination of purchasing and marketing are a hybrid of integration exchange in which joint agendas are addressed systematically, while functions retain identity and individual goals. The forums for joint agendas under co-management approaches include both dedicated team meetings and shared agenda items in other meetings ensuring that functions work with one another in a structured way and include cross-functional consideration when pursuing their own agendas (Wagner \& Eggert, in press).

Co-management working patterns include dedicated teams that operate separately from individual functions (Wynstra, Weggeman, \& van Weele, 2003). These joint innovation teams take ownership of the process and typically are formed for specific projects feeding back into specific functional areas with feedback loops for the design elements of the work and operational details to facilitate implementation and undertake mutual adaptation (Viio \& Grönroos, in press). A further type of co-management working pattern is an overlap arrangement where members of one function work on secondment in other functions. Secondees can inform their host function of relevant considerations of the home function while also learning about the host function in order to embed knowledge when they return to their home function. This process acts as a bridge to address physical location as a driver of internal integration (Gonzales-Zapatero, in press). Such close managerial approaches ensure an intensity of exchange that assists in contexts where the knowledge is complex or idiosyncratic.

Co-management is neither a transactional approach nor a relational approach but instead depends on managerial systems of work to allocate tasks and ensure accountability without either the need to monitor or the need to develop relational capital. As such, the co-management approach is an efficient way of addressing distance between functions and goal harmonization at the strategic level (Ellram \& Carr, 1994; Reck \& Long, 1988). There is a significant amount of planned interaction with clear terms of reference and responsibilities. While this may not work well in low variability, large volume repetitive cycles or in emergent innovative scenarios, it serves a host of examples in between and works as an efficient response to the problems of low internal integration.

As a graduation between the pure forms of transactional approach and integrative approach, co-management approaches to purchasing and marketing co-ordination represent a middle ground that accommodates a broad set of organizations in their integration approaches. It also reflects the changes in the business environment well with attention to known issues of cost and quality while generating co-ordinated value creating activity across functions that ensure a higher level of agility enabling the organization to respond to market and broader environmental challenges. We present co-management as the third category of 
managerial approaches to the co-ordination of purchasing and marketing in our framework (Fig. 1).

\section{Discussion and conclusions}

In this article, we brought together extant research on internal integration, drew on Industrial Marketing Management's special issue on co-management of purchasing and marketing, and supported our interpretation of the field with a case study. We outlined the internal constituencies of the organization, classified the nature of integration between purchasing and marketing functions, and conceptualized the managerial approaches adopted. The resulting framework provides a reference point in the varied and under-developed field of internal integration from which extant research can be classified and new work can gain orientation.

The case for functional integration is well supported in the literature (Bregman, 1995; Chicksand, Watson, Walker, Radnor, \& Johnston, 2012; Jüttner et al., 2007; Kotler \& Levy, 1973; Sheth et al., 2009). Despite this, the literature on functional integration is sparse with little focus on purchasing and marketing integration specifically, demonstrating a need for specific and up-to-date work in this area (Griffin \& Hauser, 1996). A more developed literature on supplier integration and a wideranging literature on marketing integration support such work and in our article we drew on this and described a framework that identifies the links between these literatures and a platform for purchasing and marketing integration. By combining situational dynamics and managerial approaches to internal integration, we described the landscape of interaction between purchasing and marketing functions and provided insight to the constituencies of the organization and the nature of managerial approaches that characterize this landscape.

The articles in this special issue contribute theoretical and empirical insight into the functional integration literature bringing meaningful perspectives from contemporary contexts. These contributions build on extant work, developing a thin field of research and establishing themes. Our framework reflects these contributions and sets out a comprehensive classification of the themes and perspectives. While this effort is not without limitations, it is the first such effort to articulate the landscape of internal integration and to establish the nature of the links to external integration. Further work is needed to provide more evidence to support and refine the framework presented here; however, it marks a crystallization of the integration literature at this juncture.

The case for integration generally and internal integration in particular is driven by changing organizational contexts, which demand shorter cycle times that favor organizational agility. Yet, internal integration is difficult to foster in many firms. Purchasing and marketing functions exist more as a legacy of previous organizational contexts than because they offer inherent contemporary benefits to the firm. Our framework assists in the identification of the organizational type and the characteristics that might be more readily expected of the internally integrated version. We also extend understanding on the importance of integration across the value chain and the relevance of less integrated approaches that apply to certain conditions.

\subsection{Implications for theory}

The work presented here in the area of internal integration of the organization, and on purchasing and marketing integration is concerned with synthesizing existing research. This literature is fragmented however and the landscape is poorly understood. The present article contributes to theory by describing the constituencies of the organization and the managerial approaches available. Extant work in these areas is organized across these themes and builds a clearer classification of the work to date. Future work might seek to make more robust classifications by testing hypotheses on the cause-effect relationships within this nomological network organizational constituencies and approaches. We outline several key outcomes of marketing and purchasing integration based on what is currently understood. These outcomes lack robust empirical assessment however and a causal structure linking internal integration with organizational performance outcomes would provide support to this work.

In particular the field would benefit from empirical investigation that seeks to verify further the boundary conditions of these classifications. Transactional managerial approaches have specific application to a limited number of fields. Further work should test its application and seek explanation of the mechanisms at work here that we touch upon but do not explore in depth. Finally, extant work draws upon a number of different theories and meta-theories that contribute to the fragmentation of the empirical conclusions and hold back the co-ordinated development of the field. We suggest the use of social exchange theory as a platform for studies in this area, which we consider will build on a developed and coherent literature in marketing with similar application to integration studies in the supply chain literature.

\subsection{Implications for managers}

The changing organizational contexts of the type that demands shorter cycle times and greater agility are never felt more keenly than by the managers who steer their organizations through this territory. Our case study gives insight into the importance of internal integration to operational efficiency. In our analysis we reason that costs efficiencies are important to low variation scenarios. Efficiencies of another sort are important to more innovation driven contexts with effective knowledge exchange across functions assisting in better response times and brand management. Managers should identify an ideal type of internal configuration that is suited to their organization and organizational context. Our classification provides a rich description of how this looks in practice across the different levels and types of integration approach and is designed to assist managers through these detailed descriptions.

While the literature developed to date on integration suggests clear benefits to the value creation process, managers should be aware that integration types across the value chain have the potential to impact on organizational performance. The merits of internal integration include aligned goal orientation and this does not stop at the boundary of the firm. Good alignment of (strategic) goals across the value chain will deliver customer value more effectively and presents as both a challenge to the manager as well as an advantage when implemented well.

\subsection{Limitations}

Our research is limited by a narrow empirical focus on one case study in one industry, which, while methodologically justified, limits generalizability of the interpretations taken from this case study. While the work is supported by extensive empirical and theoretical literature, this is wide ranging in method and context and limits the universality of the findings. As the field develops, the body of empirical evidence and theoretical understanding will address this problem and will also facilitate refinement of the framework that we present. A fledgling literature in the field of purchasing and marketing integration is a limited foundation for the work, but it is hoped that by reconceiving this area of academic inquiry we contribute both clarity and an improved foundation for future research.

In this article we classify a poorly aligned body of research. Further research is needed to provide more robust support for the findings. Such insights will be effective in this task if they employ a narrow set of theoretical lenses and a more consistent array of methods. Stronger empirical evidence is needed to test and support current interpretation of the dynamics and managerial approaches to purchasing and marketing co-ordination. This may be achieved by larger scale studies using multiple respondents. 


\section{References}

Achrol, R., \& Kotler, P. (1999). Marketing in the network economy. Journal of Marketing, 63(4), 146-163.

Bals, L., Hartmann, E., \& Ritter, T. (2009). Barriers of purchasing departments' involvement in marketing service procurement. Industrial Marketing Management, 38(8), 892-902.

Blau, P. (1964). Exchange and power in social life. New Jersey: Wiley \& Sons.

Blois, K., \& Ivens, B. (2006). Measuring relational norms: some methodological issues. European Journal of Marketing, 40(3/4), 352-365.

Blonska, A., Storey, C., Rozemeijer, F., Wetzels, M., \& Ruyter, K. (2013). Decomposing the effect of supplier development on relationship benefits: The role of relational capital. Industrial Marketing Management, 42(8), 1295-1306.

Bocconcelli, R., \& Tunisini, A. (2012). The relationship between marketing and purchasing for value innovation in business-to-business markets. The IMP Journal, 6(1), 85-97.

Bregman, R. (1995). Integrating marketing, operations, and purchasing to create value. OMEGA: International Journal of Management Science, 23(2), 159-172.

Carmeli, A., \& Schaubroeck, J. (2006). Top management team behavioral integration, decision quality, and organizational decline. The Leadership Quarterly, 17(5), 441-453.

Chicksand, D., Watson, G., Walker, H., Radnor, Z., \& Johnston, R. (2012). Theoretical perspectives in purchasing and supply chain management: An analysis of the literature. Supply Chain Management: An International Journal, 17(4), 454-472.

Cook, K., \& Emerson, R. (1978). Power, equity and commitment in exchange networks. American Sociological Review, 43(5), 721-739.

Coviello, N., Brodie, R., Danaher, P., \& Johnston, W. (2002). How firms relate to their markets: An empirical examination of contemporary marketing practices. Journal of Marketing, 66(3), 33-46.

Day, G. (1999). Aligning organizational structure to the market. Business Strategy Review, 10(3), 33-46.

de Ruyter, K., \& Wetzels, M. (2000). The marketing-finance interface: A relational exchange perspective. Journal of Business Research, 50(2), 209-215.

Dess, G., Rasheed, A., McLaughlin, K., \& Priem, R. (1995). The new corporate architecture. Academy of Management Executive, 9(3), 7-18.

Ellegaard, C., \& Koch, C. (2012). The effects of low internal integration between purchasing and operations on suppliers' resource mobilization. Journal of Purchasing and Supply Management, 18(3), 148-158.

Ellram, L., \& Carr, A. (1994). Strategic purchasing: A history and review of the literature. International Journal of Purchasing and Materials Management, 30(2), 10-18.

Ernst, H., Hoyer, W., \& Rubsaamen, C. (2010). Sales, marketing, and research-anddevelopment cooperation across new product development stages: Implications for success. Journal of Marketing, 74(5), 80-92.

Flynn, B., Huo, B., \& Zhao, X. (2010). The impact of supply chain integration on performance: A contingency and configuration approach. Journal of Operations Management, 28(1), 58-71.

Gonzales-Zapatero (2015). Determinants of functional integration during new product development: The purchasing-marketing link. Industrial Marketing Management (in press).

Granovetter, M. (1985). Economic action and social structure. American Journal of Sociology, 91(3), 481-510

Griffin, A., \& Hauser, J. (1996). Integrating R\&D and marketing: A review and analysis of the literature. Journal of Product Innovation Management, 13(3), 191-215.

Gulati, R. (1995). Does familiarity breed trust? The implications of repeated ties for contractual choice in alliances. Academy of Management Journal, 38(1), 85-112.

Gulati, R., \& Oldroyd, J. (2005, April). The quest for customer focus. Harvard Business Review, 83(4), 92-101.

Gummesson, E., \& Polese, F. (2009). B2B is not an island! Journal of Business E' Industrial Marketing, 24(5/6), 337-350.

Hingley, M.K., Lindgreen, A., \& Casswell, B. (2006). Supplier-retailer relationships in UK fresh produce supply chain. Journal of International Food \&' Agribusiness Marketing, $18(1 / 2), 49-86$.

Homans, G. (1950). The human group. New York, NY: Harcourt, Brace \& World, Inc.

Homburg, C., Jensen, O., \& Krohmer, H. (2008). Configurations of marketing and sales: A taxonomy. Journal of Marketing, 72(March), 133-154.

Houston, M., Walker, B., Hutt, M., \& Reingen, P. (2001). Cross-unit competition for a market charter: The Enduring Infiuence of Structure. Journal of Marketing, 65(2), 19-34.

Jüttner, U., Christopher, M., \& Baker, S. (2007). Demand chain management-integrating marketing and supply chain management. Industrial Marketing Management, 36(3), 377-392.

Khan, K., \& Mentzer, J. (1998). Marketing integration with other departments. Journal of Business Research, 42(1), 53-62.
Kotler, P., \& Levy, S. (1973). Buying is marketing too! Journal of Marketing, 37(1), 54-59.

Krohmer, H., Homburg, C., \& Workman, J. (2002). Should marketing be cross-functional? Conceptual development and international empirical evidence. Journal of Business Research, 55(6), 451-465.

Lindgreen, A., Vanhamme, J., van Raaij, E., \& Johnston, W. (2013). Go configure: The mix of purchasing practices to choose for your supply base. California Management Review, 55(2), 72-96.

Lui, W Gong Y \& Liu J. (2014). When do business units benefit more from collective citizenship behavior of management teams? An upper echelons perspective. Journal of Applied Psychology, 99(3), 523-534.

Luo, Y. (2002). Building trust in cross-cultural collaborations: Toward a contingency perspective. Journal of Management, 28(5), 669-694.

Matthyssens, P. (2015). The marketing/purchasing interface as a tool to achieve value creation. Industrial Marketing Management (in press).

Maurer, I., Bartsch, V., \& Ebers, M. (2011). The value of intra-organizational social capital: How it fosters knowledge transfer, innovation performance, and growth. Organization Studies, 32(2), 157-185.

Moorman, C., \& Rust, R. (1999). The role of marketing. Journal of Marketing, 63(4), 180-197.

Noordhoff, C., Kyriakopoulos, K., Moorman, C., Pauwels, P., \& Dellaert, B. (2011). The bright side and dark side of embedded ties in business-to-business innovation. Journal of Marketing, 75(5), 34-52.

Piercy, N. (2009). Strategic relationships between boundary-spanning functions: Aligning customer relationship management with supplier relationship management. Industrial Marketing Management, 38(8), 857-864.

Reck, R., \& Long, B. (1988). Purchasing: A competitive weapon. Journal of Purchasing and Materials Management, 24(3), 2-8.

Ruekert, R., \& Walker, O. (1987). Marketing's interaction with other functional units: A conceptual framework and empirical evidence. Journal of Marketing 51(1), 1-19.

Sharma, A., \& LaPlaca, P. (2005). Marketing in the emerging era of build-to-order manufacturing. Industrial Marketing Management, 34, 476-486.

Sheth, J., \& Parvatiyar, A. (1995). The evolution of relationship marketing. International Business Review, 4(4), 397-418.

Sheth, J., Sharma, A., \& Gopalkrishnan, R. (2009). Why integrating purchasing with marketing is both inevitable and beneficial. Industrial Marketing Management, 38(8) 865-871.

Srivastsava, R., Shervani, T., \& Fahey, L. (1999). Marketing, business processes, and shareholder value: An organizationally embedded view of marketing activities and the discipline of marketing. Journal of Marketing, 63(4), 168-179.

Thibaut, J.W., \& Kelley, H.H. (1959). The social psychology of groups. New York, NY: John Wiley \& Sons.

Toon, M., Robson, M.J., \& Morgan, R.E. (2012). A value-in-process analysis of relationship interactions in non-equity alliances. Industrial Marketing Management, 41(1), 186-196.

Trent, R., \& Monczka, R. (2003). International purchasing and global sourcing: What are the differences? The Journal of Supply Chain Management, 39(4), 26-37.

Ulaga, A., \& Eggert, W. (2006). Relationship value and relationship quality. European Journal of Marketing, 40(3/4), 311-327.

Vargo, S.L., \& Lusch, R.F. (2004). Evolving to a new dominant logic for marketing. Journal of Marketing, 68(1), 1-17.

Viio, P., \& Grönroos, C. (2015). How buyer-seller relationship orientation affects adaptation of sales processes to the buying process. Industrial Marketing Management (in press).

Wagner, S.M., \& Eggert, A. (2015). Co-management of purchasing and marketing: Why, when and how? Industrial Marketing Management (in press).

Williams, A., Giunipero, L., \& Henthorne, T. (1994). The cross-functional imperative: The case of marketing and purchasing. International Journal of Purchasing and Materials Management, 30(3), 29-33.

Wind, Y. (2005). Marketing as an engine of business growth: A cross-functional perspective. Journal of Business Research, 58(7), 863-873.

Wynstra, F., Weggeman, M., \& van Weele, A. (2003). Exploring purchasing integration in product development. Industrial Marketing Management, 32(1), 69-83.

Ziggers, G.W., \& Henseler, J. (2015). The reinforcing effect of a firm's customer orientation and supply base orientation on performance. Industrial Marketing Management (in press). 